\title{
Oncologic Outcome of Radical Prostatectomy as Monotherapy for Men with High-risk Prostate Cancer
}

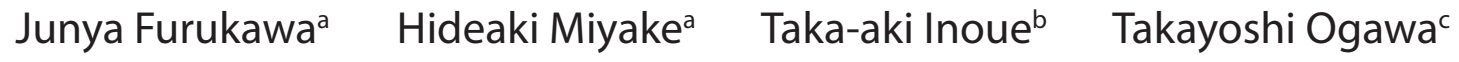 \\ Hirokazu Tanaka ${ }^{d}$ Masato Fujisawa ${ }^{a}$ \\ aDivision of Urology, Kobe University Graduate School of Medicine, Kobe; 'bepartment of Urology, Hyogo Cancer Center, Akashi; \\ 'Department of Urology, Himeji Red Cross Hospital, Himeji; 'Department of Urology, Shinko Hospital, Kobe, Japan
}

\section{Key Words}

High-risk prostate cancer • Radical prostatectomy •

Biochemical recurrence

\begin{abstract}
Background: The objective of this study was to review our experience with radical prostatectomy (RP) as monotherapy for men with high-risk prostate cancer (PCa). Patients and Methods: This study included 382 consecutive patients who were diagnosed with high-risk PCa according to the D'Amico definition and subsequently underwent RP without neoadjuvant therapy. Biochemical recurrence (BR) was defined as a serum prostate-specific antigen (PSA) level $\geq 0.2 \mathrm{ng} / \mathrm{ml}$ on two consecutive measurements, and none of the patients received any adjuvant therapies until their serum PSA levels reached $\geq 0.4 \mathrm{ng} / \mathrm{ml}$. Results: The median preoperative serum PSA level in these 382 patients was $15.9 \mathrm{ng} / \mathrm{ml}$. Pathological stages $\geq$ pT2c and Gleason scores $\geq 8$ were observed in 288 and 194 patients, respectively. During the observation period (median, 48.0 months), BR occurred in 134 patients, and the 5-year BR-free survival rate was $60.1 \%$; however, no patient died of cancer progression. Multivariate analysis identified capsular invasion, seminal vesicle invasion, and surgical margin status as independent predictors of BR. Con-
\end{abstract}

\section{KARGER}

Fax +4161306 1234

E-Mail karger@karger.ch

www.karger.com
(C) 2015 S. Karger AG, Basel

$1015-9770 / 14 / 0092-0067 \$ 38.00 / 0$

Accessible online at:

www.karger.com/cur clusions: Comparatively favorable cancer control could be achieved using RP as monotherapy for men with high-risk $\mathrm{PCa}$; however, RP alone may be insufficient for patients with capsular invasion, seminal vesicle invasion, and/or surgical margin positivity.

Copyright $\odot 2015$ S. Karger AG, Basel

\section{Introduction}

Prostate cancer $(\mathrm{PCa})$ is the most common malignancy and the second leading cause of cancer-related death in men in Western industrialized countries [1]. Despite the widespread use of prostate-specific antigen (PSA) screening, approximately 15-25\% of PCa patients are still diagnosed with locally advanced disease [2]. In 1998, D'Amico et al. [3] proposed a useful risk classification using pretreatment clinicopathological parameters, which remains the most widely accepted and validated system in a number of reports $[4,5]$. In this system, patients with a serum PSA level $>20 \mathrm{ng} / \mathrm{ml}$, Gleason score of $8-10$, and/or clinical stage $\geq \mathrm{T} 2 \mathrm{c}$ are categorized as a high-risk group [3]. 
Table 1. Patient characteristics

\begin{tabular}{|c|c|}
\hline Patient demography & Value \\
\hline Age, years (range) & $67.8(50-79)$ \\
\hline Prostate-specific antigen, ng/mL (range) & $15.9(2.9-65.4)$ \\
\hline \multicolumn{2}{|l|}{ Clinnical stage } \\
\hline T1c & $69(18.1 \%)$ \\
\hline $\mathrm{T} 2 \mathrm{a}$ & $89(23.3 \%)$ \\
\hline $\mathrm{T} 2 \mathrm{~b}$ & $59(15.5 \%)$ \\
\hline $\mathrm{T} 2 \mathrm{c}$ & $109(28.5 \%)$ \\
\hline $\mathrm{T} 3$ & $56(14.6 \%)$ \\
\hline \multicolumn{2}{|l|}{ Biopsy Gleason score } \\
\hline$\leq 6$ & $75(19.6 \%)$ \\
\hline 7 & $113(29.6 \%)$ \\
\hline$\geq 8$ & $194(50.8 \%)$ \\
\hline \multicolumn{2}{|l|}{ Pathological stage } \\
\hline $\mathrm{pT} 2 \mathrm{a}$ & $36(9.4 \%)$ \\
\hline pT2b & $58(15.2 \%)$ \\
\hline $\mathrm{pT} 2 \mathrm{c}$ & $133(34.8 \%)$ \\
\hline pT3a & $94(24.6 \%)$ \\
\hline $\mathrm{pT} 3 \mathrm{~b}$ & $61(16.0 \%)$ \\
\hline \multicolumn{2}{|l|}{ Gleason score } \\
\hline$\leq 6$ & $40(10.5 \%)$ \\
\hline 7 & $228(59.7 \%)$ \\
\hline$\geq 8$ & $114(29.8 \%)$ \\
\hline \multicolumn{2}{|l|}{ Extracapsular extension } \\
\hline Negative & $235(61.5 \%)$ \\
\hline Positive & $147(38.5 \%)$ \\
\hline \multicolumn{2}{|l|}{ Seminal vesicle invasion } \\
\hline Negative & $321(84.0 \%)$ \\
\hline Positive & $61(16.0 \%)$ \\
\hline \multicolumn{2}{|l|}{ Perineural invasion } \\
\hline Negative & $113(29.6 \%)$ \\
\hline Positive & $269(70.4 \%)$ \\
\hline \multicolumn{2}{|l|}{ Lymphovascular invasion } \\
\hline Negative & $233(61.0 \%)$ \\
\hline Positive & $149(39.0 \%)$ \\
\hline \multicolumn{2}{|l|}{ Lymph node status } \\
\hline $\mathrm{pN} 0$ & $361(94.5 \%)$ \\
\hline $\mathrm{pN} 1$ & $21(5.5 \%)$ \\
\hline \multicolumn{2}{|l|}{ Surgical margin status } \\
\hline Negative & $201(52.6 \%)$ \\
\hline Positive & $181(47.4 \%)$ \\
\hline
\end{tabular}

Of the 2 major recommended options, external beam radiotherapy (EBRT) rather than radical prostatectomy (RP) is likely to be selected as the primary treatment for patients with localized high-risk $\mathrm{PCa}$, due to the significant morbidity associated with the low probability of a complete cure by surgery alone in this cohort of patients $[6,7]$. To date, however, a reliable randomized trial comparing RP and EBRT has not been conducted in men with high-risk PCa. Several retrospective studies on clinically localized PCa have favored RP [8-10], whereas others have favored EBRT [11, 12]; therefore, the optimal treatment for men with high-risk PCa remains controversial.
Table 2. Uni- and multivariate analyses of several pathological factors for predicting biochemical recurrence-free survival

\begin{tabular}{|c|c|c|c|c|}
\hline Variables & $\begin{array}{c}\text { Univariate ar } \\
\text { Hazard ratio }\end{array}$ & analysis & $\frac{\text { Univariate }}{\text { Hazard ratio }}$ & analysis \\
\hline $\begin{array}{l}\text { Gleason score } \\
(<8 \text { vs. } 8)\end{array}$ & 1.43 & $<0.0001$ & 1.32 & 0.0021 \\
\hline $\begin{array}{l}\text { Extracapsular extension } \\
\quad \text { (negative vs. positive) }\end{array}$ & 3.16 & $<0.0001$ & 1.55 & 0.0439 \\
\hline $\begin{array}{l}\text { Seminal vesicle invasion } \\
\text { (negative vs. positive) }\end{array}$ & 4.42 & $<0.0001$ & 2.47 & $<0.0001$ \\
\hline $\begin{array}{l}\text { Lymphovascular invasion } \\
\text { (negative vs. positive) }\end{array}$ & 1.96 & $<0.0001$ & 1.10 & 0.4882 \\
\hline $\begin{array}{l}\text { Perineural invasion } \\
\text { (negative vs. positive) }\end{array}$ & 2.69 & $<0.0001$ & 1.46 & 0.2136 \\
\hline $\begin{array}{l}\text { Lymph node status } \\
\text { (pN0 vs. pN1) }\end{array}$ & 4.13 & $<0.0001$ & 1.49 & 0.1869 \\
\hline $\begin{array}{l}\text { Surgical margin status } \\
\quad \text { (negative vs. positive) }\end{array}$ & 2.83 & $<0.0001$ & 1.84 & 0.0059 \\
\hline
\end{tabular}

$\mathrm{RP}$ has been shown to provide excellent local control, accurately stage the disease, and remove benign sources of PSA, which makes it possible to promptly identify biochemical recurrence (BR) and initiate subsequent treatment in an optimal time frame [13]. Several previous studies suggested that these advantages of RP could be applied to patients with high-risk PCa as well, resulting in the achievement of favorable cancer control by combining other therapeutic modalities [6, 7, 13-18]. For example, Meng et al. [14] reported the 10-year outcomes from the CaPSURE database for men with high-risk PCa treated with RP, showing 95\% cancer-specific survival and $80 \%$ overall survival. However, the significance of $\mathrm{RP}$ as monotherapy for high-risk PCa has not been well characterized. Accordingly, we retrospectively assessed the clinical outcomes in a total of 382 consecutive patients with high-risk PCa who underwent RP without neoadjuvant therapy and received no postoperative adjuvant therapies until their serum PSA levels reached $\geq$ $0.4 \mathrm{ng} / \mathrm{ml}$.

\section{Patients and Methods}

Informed consent for conducting this study was obtained from each patient, and the study design was approved by the Research Ethics Committee of our institutions. This study included a total of 382 consecutive patients who were diagnosed with clinically localized high-risk PCa, and subsequently underwent RP and pelvic lymphadenectomy without any neoadjuvant therapies at our institutions between January 2004 and December 2013. Highrisk $\mathrm{PCa}$ was defined as those with a serum PSA level $>20 \mathrm{ng} /$ 


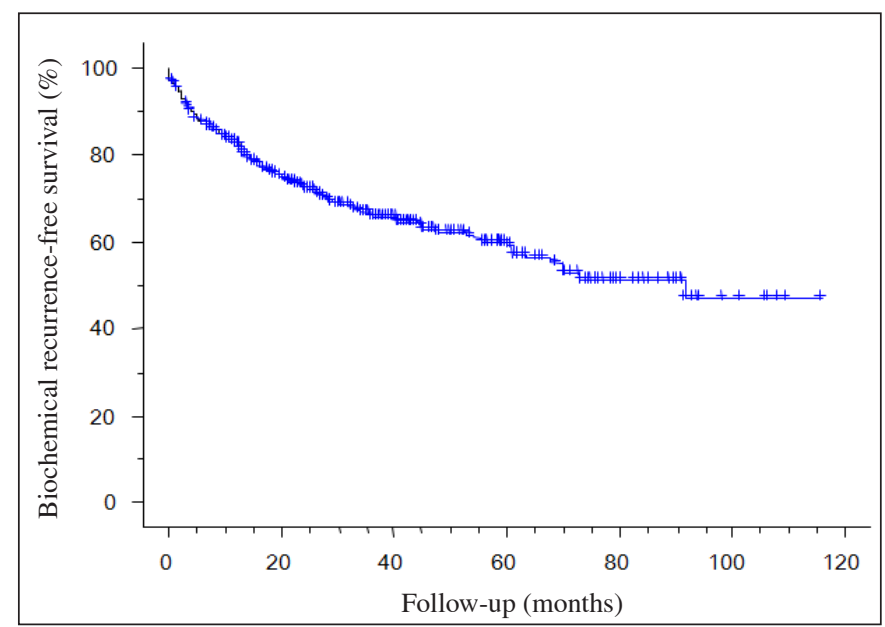

Fig. 1. Biochemical recurrence-free survival of 382 patients with high-grade prostate cancer who underwent radical prostatectomy.

$\mathrm{ml}$, Gleason score of $8-10$, and/or clinical stage $\geq \mathrm{T} 2 \mathrm{c}$ according to the D'Amico criteria [3]. Prior to RP, PCa was diagnosed histopathologically using specimens obtained from systematic transrectal ultrasound-guided needle biopsy and/or transurethral resection of the prostate. The staging procedures included digital rectal examination, transrectal ultrasonography, serum PSA assay, computed tomography, magnetic resonance imaging, and/or bone scan.

In this series, RP was performed based on the procedure described by Walsh in combination with modifications by others $[19,20]$. As a rule, the anatomical extent of bilateral lymphadenectomy was the obturator fossa and external iliac region, and the median number of lymph nodes resected per patient was 16.5 (range 5-26). All pathological examinations were generally performed under the guidance of a single pathologist based on the 2010 TNM classification system. The surface of the resected specimen was inked, fixed, and whole-mount step sections were cut transversely at 3-mm intervals from the apex of the prostate to the tips of the seminal vesicles. A positive surgical margin was defined by the presence of cancer cells at the inked margin. As for the Gleason grading for both biopsy and radical prostatectomy specimens, the modified International Society of Urological Pathology 2005 Gleason grading system was used [21].

After RP, patients were followed by periodic measurement of the serum PSA value at least every 3 months for the first 2 years, and every 6 months thereafter. BR was defined as a PSA level $\geq 0.2 \mathrm{ng} / \mathrm{ml}$ on 2 consecutive measurements. Irrespective of the pathological findings suggesting a poor prognosis, none of the patients were treated with any postoperative adjuvant therapies until their serum PSA levels reached $\geq 0.4 \mathrm{ng} / \mathrm{ml}$.

In this study, all statistical analyses were performed using Statview 5.0 software (Abacus Concepts, Inc., Berkeley, CA, USA), and $\mathrm{p}$ values $<0.05$ were considered significant. The BR-free survival rates of the included patients were calculated employing the Kaplan-Meier method, and the differences were determined

Radical Prostatectomy for High-risk Prostate Cancer by the log-rank test. The prognostic significance of certain factors was assessed using the Cox proportional hazards regression model.

\section{Results}

Table 1 summarizes the clinicopathological characteristics of the 382 high-risk PCa patients included in this study. Of these 382, $116(30.4 \%), 194$ (50.8\%), and $288(75.4 \%)$ were judged to have a serum PSA level > $20 \mathrm{ng} / \mathrm{ml}$, Gleason score of $8-10$, and clinical stage $\geq$ T2c, respectively. During the observation period of this series (median 48.0 months; range 1-115 months), BR occurred in 134 of the 382 patients $(35.1 \%)$, and the 1-, 3 -, and 5-year BR-free survival rates were $79.2 \%, 68.4 \%$, and $60.1 \%$, respectively (fig. 1 ).

We then evaluated the impact of several pathological parameters on the prediction of BR-free survival in the 382 patients. As shown in Table 2, univariate analysis using the Cox proportional hazards regression model showed that the Gleason score, extracapsular extension, seminal vesicle invasion (SVI), lymphovascular invasion, perineural invasion, lymph node metastasis, and surgical margin status (SMS) were significant predictors for BR-free survival. Moreover, the Gleason score, extracapsular extension, SVI, and SMS appeared to be independently related to BR-free survival on multivariate analysis of these 8 significant parameters determined by univariate analysis. BR-free survival curves according to these 4 independent predictive factors for BR are shown in fig. 2, and significant differences in BR-free survival with respect to all of these 4 factors were noted.

To more precisely characterize the prognostic features in this cohort of patients, we classified patients into 3 groups according to the positive number of 4 independent risk factors for BR-free survival identified by multivariate analysis; that is, BR occurred in 16 of 112 patients who were negative for all risk factors (14.3\%), 66 of 203 positive for 1 or 2 risk factors (32.6\%), and 52 of 67 positive for 3 or 4 risk factors $(77.7 \%)$. As shown in fig. 3, there were significant differences in BR-free survival among these 3 groups.

\section{Discussion}

Although an increasing proportion of men with highrisk $\mathrm{PCa}$ receive combined treatment with EBRT and hormonal therapy, the optimal management of high-risk PCa remains controversial. However, with a marked de- 


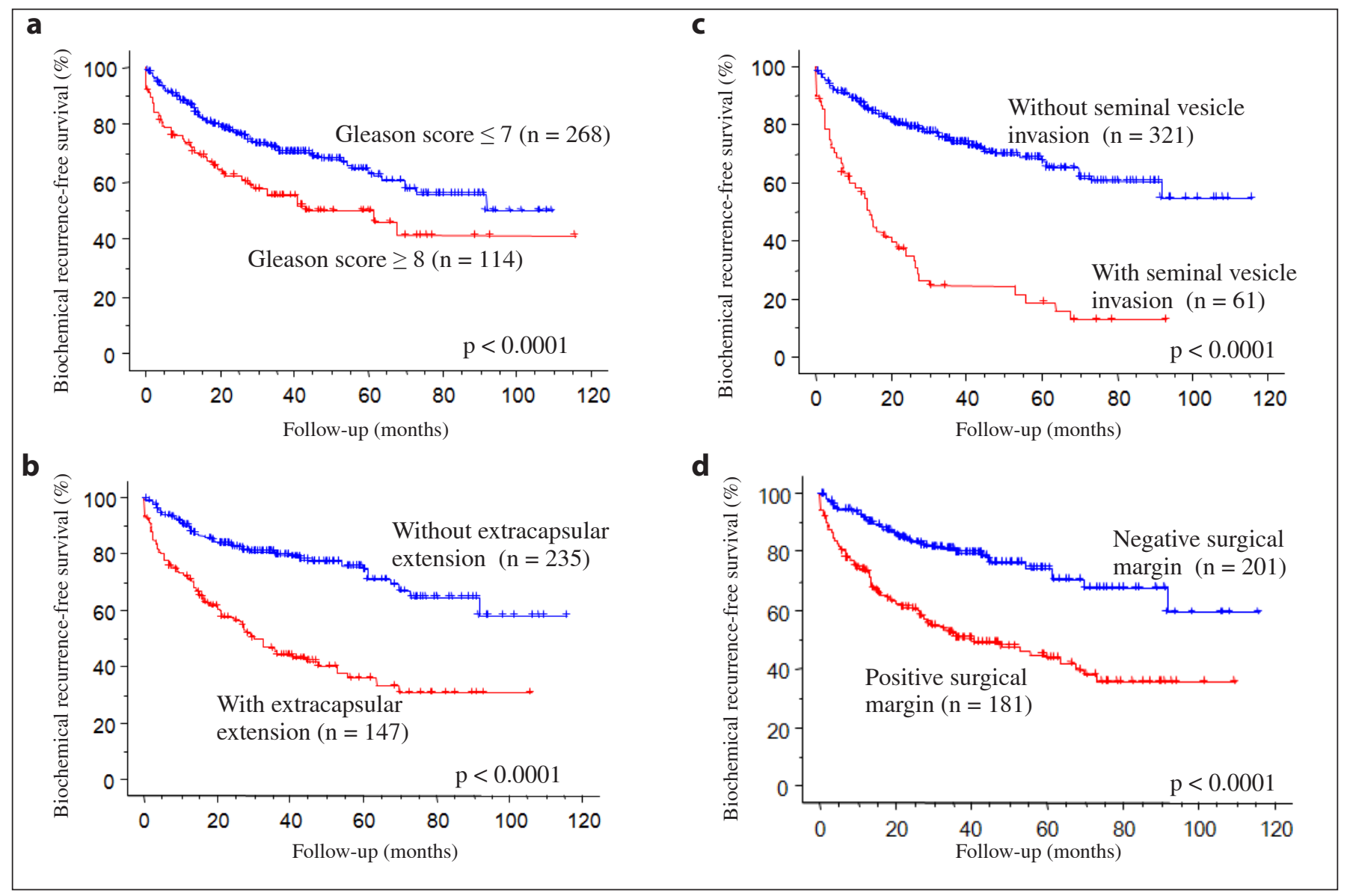

Fig. 2. a Biochemical recurrence (BR)-free survival of patients with high-grade prostate cancer (PCa) who underwent radical prostatectomy (RP) according to the Gleason score. b BR-free survival of patients with high-grade PCa who underwent RP according to extracapsular extension. c BR-free survival of patients with high-grade PCa who underwent RP according to seminal vesicle invasion. d BR-free survival of patients with high-grade PCa who underwent RP according to the surgical margin status.

crease in the incidence of severe adverse events following RP due to recent advances in anatomical knowledge and improvements in surgical techniques [22], it has become common for PCa patients to choose avoiding the complications associated with hormonal therapy, which include hot flash, impotence, loss of libido, gynecomastia, osteopenia, and an increase in the risk of cardiovascular disease [23]. Accordingly, it has become attractive for patients with high-risk PCa, particularly younger men, to consider RP as an alternative option to EBRT combined with hormonal therapy. In fact, there have been several studies showing favorable cancer control by RP in men with high-risk PCa [6, 7, 13-18]; however, these studies included some patients, albeit a very small proportion, who received additional therapy as either neoadjuvant or adjuvant setting. Considering these findings, in this study, we retrospectively assessed the prognostic outcomes in a total of 382 patients with high-risk $\mathrm{PCa}$ who underwent RP as monotherapy in order to address the significance of surgical treatment for patients with high-risk PCa.

In this series, $<60 \%$ of the included patients had pathologically organ-confined disease; however, BR was noted in $35.1 \%$ of the included patients, and there was no patient who died of PCa progression during the median observation period of 48.0 months. Despite being a comparatively shorter follow-up interval, these outcomes may be comparable to those in previous studies [5-7, 1318]. For example, Loeb et al. [7] reported that at a median follow-up of 8 years in 175 high-risk PCa patients undergoing RP, BR, local recurrence, and metastatic dis- 


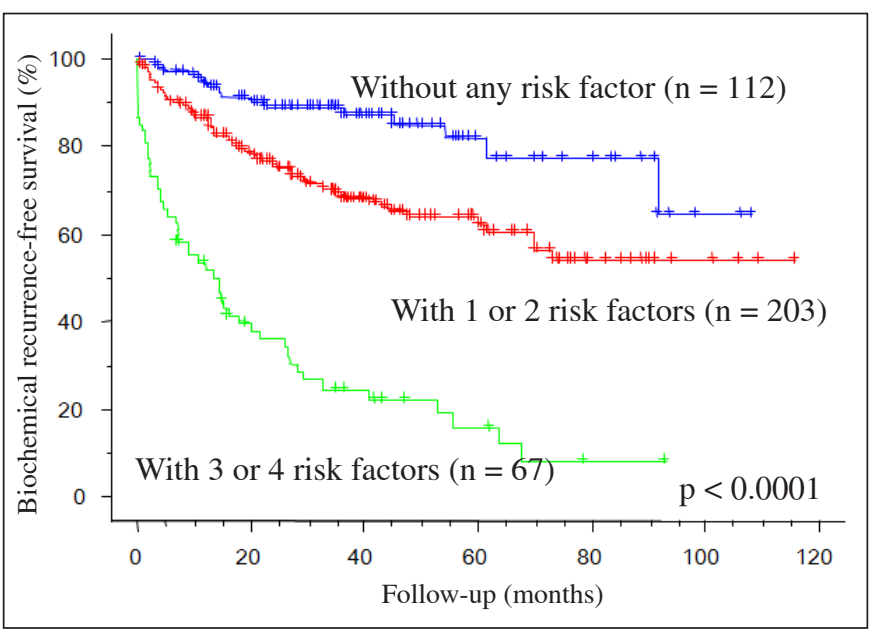

Fig. 2. Biochemical recurrence (BR)-free survival of patients with high-grade prostate cancer who underwent radical prostatectomy according to the positive number of independent risk factors for postoperative BR, including the Gleason score, extracapsular extension, seminal vesicle invasion, and surgical margin status.

ease occurred in $29 \%, 3 \%$, and $13 \%$, respectively, and $6 \%$ died of PCa. Similarly, Boorjian et al. [5] assessed data on 1,513 men with high-risk PCa who received RP, and showed that the 10-year BR-free, systemic progression-free, and cancer-specific survival rates were 55\%, $89 \%$ and $95 \%$, respectively. Collectively, these findings suggest that a large proportion of patients with high-risk PCa could be cured by surgical therapy, irrespective of additional treatments.

It is of interest to identify factors associated with BRfree survival after RP in patients with high-risk PCa. In this series, of the several pathological parameters examined, the Gleason score, extracapsular extension, SVI, and SMS were identified as independent predictive factors of BR-free survival on multivariate analysis. The present outcomes are consistent with several previous studies [13-18]. For example, Ploussard et al. [15] reported that the Gleason score $\geq 8$, pathological stage $\geq$ pT3, positive SM, and lymph node involvement were independently associated with BR-free survival in 813 high-risk PCa patients who were treated with RP. These findings suggest the important role of conventional pathological factors in RP specimens in the prediction of biochemical outcomes in patients with high-risk $\mathrm{PCa}$ even after treatment with surgical monotherapy.

Another point of interest is to examine whether or not prognostic prediction could be refined by combining plural risk factors for BR simultaneously. In this series, based

Radical Prostatectomy for High-risk Prostate Cancer on the outcomes achieved by multivariate analysis, the 382 patients were classified into the following 3 groups according to the positive number of independent risk factors for BR: negative for all risk factors, positive for 1 or 2 risk factors, and positive for 3 or 4 risk factors, and significant differences in BR-free survival among these 3 groups were noted. Abern et al. [18] reported that it was useful to classify high-risk PCa patients using the Gleason score, pathological T stage, and lymph nodal status into favorable and unfavorable prognostic groups, while Ploussard et al. [15] proposed a risk stratification system following RP for high-risk PCa based on extracapsular extension, SVI, and SMS. Taken together, a simultaneous consideration of the 4 major risk factors identified in this series (Gleason score, extracapsular extension, SVI, and SMS) may contribute to develop a novel predicting system that can be more closely related to BR after RP for men with high-risk PCa, and thus allow better individualization of the postoperative follow-up and management in this category of patients.

Here, we would like to describe the limitations of this study. Firstly, despite the comparatively larger number of patients included in this study, the observation period was not long enough to draw definitive conclusions, especially regarding those associated with prognostic issues. Thus, it will be necessary to confirm whether the findings of this study could be consistent with those obtained after extending the observation period. Secondly, the current cohort represents selected patients who were regarded as optimal candidates for surgery; therefore, the present findings could not be applied to all men with high-risk PCa. Thirdly, the D'Amico classification system is one of many criteria for the definition of high-risk $\mathrm{PCa}$, and inconsistent outcomes were shown depending on the risk classification system [24]. Fourthly, a total of 17 surgeons were involved as operators in this series; and although they were all highly experienced, the oncological outcomes following RP could be influenced by differences in the surgical techniques of each surgeon, particularly those associated with local wide resection of tissues surround the prostate [25]. Finally, it should be carefully evaluated whether the strategy of additional postoperative therapy in this series negatively affect the prognostic outcomes, since the benefit of early introduction of adjuvant therapies in patients likely to develop disease recurrence, such as those with a positive surgical margin, is widely recognized.

In conclusion, to our knowledge, this is the first study to show that RP as monotherapy could provide encouraging mid-term oncological outcomes for the management 
of high-risk PCa patients classified based on the D'Amico system, achieving a $60.1 \%$ BR-free survival rate at 5 years after surgery. These findings indicate that despite its utility, the D'Amico criteria define a heterogeneous cohort as a high-risk group; therefore, we developed a system to more precisely predict prognostic outcomes in high-risk PCa patients undergoing RP using a positive number of independent risk factors for $\mathrm{BR}$, including the
Gleason score, extracapsular extension, SVI, and SMS. Collectively, these findings suggest that although some proportion of patients with high-risk PCa ultimately require a multimodal therapeutic approach following RP, it may still be suitable for this category of patients to be treated with surgical monotherapy considering the potential advantages in RP.

\section{References}

1 Heidenreich A, Bellmunt J, Bolla M, Joniau S, Mason M, Matveev V, Mottet N, Schmid HP, van der Kwast T, Wiegel T, Zattoni F: EAU guidelines on prostate cancer. Part 1:screening, diagnosis, and treatment of clinically localized disease. Eur Urol 2011;59:61-71.

2 Xylinas E, Dache A, Roupret M: Is radical prostatectomy a viable therapeutic option in clinically locally advanced (cT3) prostate cancer? BJU Int 2010;106:1596-600.

3 D'Amico AV, Whittington R, Malkowicz SB, Schultz D, Blank K, Broderick GA, Tomaszewski JE, Renshaw AA, Kaplan I, Beard CJ, Wein A: Biochemical outcome after radical prostatectomy, external beam radiation therapy, or interstitial radiation therapy for clinically localized prostate cancer. JAMA 1998; 280:969-974.

4 Hernandez DJ, Nielsen ME, Han M, Partin AW: Contemporary evaluation of the D'amico risk classification of prostate cancer. Urology 2007;70:931-935.

5 Boorjian SA, Karnes RJ, Rangel LJ, Bergstralh EJ, Blute ML: Mayo Clinic validation of the D'amico risk group classification for predicting survival following radical prostatectomy. J Urol 2008;179:1354-1360.

6 Freedland SJ, Partin AW, Humphreys EB, Mangold LA, Walsh PC: Radical prostatectomy for clinical stage T3a disease. Cancer 2007;109:1273-1278.

7 Loeb S, Schaeffer EM, Trock BJ, Epstein JI, Humphreys EB, Walsh PC: What are the outcomes of radical prostatectomy for high-risk prostate cancer? Urology 2010;76:710-714.

8 Zelefsky MJ, Eastham JA, Cronin AM, Fuks Z, Zhang Z, Yamada Y, Vickers A, Scardino PT: Metastasis after radical prostatectomy or external beam radiotherapy for patients with clinically localized prostate cancer: a comparison of clinical cohorts adjusted for case mix. J Clin Oncol 2010;28:1508-1513.

9 Boorjian SA, Karnes RJ, Viterbo R, Rangel LJ, Bergstralh EJ, Horwitz EM, Blute ML, Buyyounouski MK: Long-term survival after radical prostatectomy versus external-beam radiotherapy for patients with high-risk prostate cancer. Cancer 2011;117:2883-9281.
10 Albertsen PC, Hanley JA, Penson DF, Barrows G, Fine J: 13-year outcomes following treatment for clinically localized prostate cancer in a population based cohort. J Urol 2007;177:932-936.

11 Fletcher SG, Mills SE, Smolkin ME, Theodorescu D: Case-matched comparison of contemporary radiation therapy to surgery in patients with locally advanced prostate cancer. Int J Radiat Oncol Biol Phys 2006;66: 1092-1099.

12 Grimm P, Billiet I, Bostwick D, Dicker AP, Frank S, Immerzeel J, Keyes M, Kupelian P, Lee WR, Machtens S, Mayadev J, Moran BJ, Merrick G, Millar J, Roach M, Stock R, Shinohara K, Scholz M, Weber E, Zietman A, Zelefsky M, Wong J, Wentworth S, Vera $\mathrm{R}$, Langley S: Comparative analysis of prostate-specific antigen free survival outcomes for patients with low, intermediate and high risk prostate cancer treatment by radical therapy. Results from the Prostate Cancer Results Study Group. BJU Int 2012;109(Suppl 1):22-29.

13 Ischia J, Gleave M: Radical prostatectomy in high-risk prostate cancer. Int J Urol 2013;20: 290-300.

14 Meng MV, Elkin EP, Latini DM, Duchane J, Carroll PR: Treatment of patients with high risk localized prostate cancer: results from cancer of the prostate strategic urological research endeavor (CaPSURE). J Urol 2005; 173:1557-1561.

15 Ploussard G, Masson-Lecomte A, Beauval JB, Ouzzane A, Bonniol R, Buge F, Fadli S, Rouprêt M, Rebillard X, Gaschignard N, Pfister C, Villers A, Soulié M, Salomon L: Radical prostatectomy for high-risk prostate cancer defined by preoperative criteria: oncologic follow-up in national multicenter study in 813 patients and assessment of easy-to-use prognostic substratification. Urology 2011; 78:607-613.

1616 Bach C, Pisipati S, Daneshwar D, Wright M, Rowe E, Gillatt D, Persad R, Koupparis A: The status of surgery in the management of high-risk prostate cancer. Nat Rev Urol 2014:11:342-351.
17 Ritch CR, You C, May AT, Herrell SD, Clark PE, Penson DF, Chang SS, Cookson MS, Smith JA Jr, Barocas DA: Biochemical recurrence-free survival after robotic-assisted laparoscopic vs open radical prostatectomy for intermediate- and high-risk prostate cancer. Urology 2014;83:1309-1315.

18 Abern MR, Terris MK, Aronson WJ, Kane CJ, Amling CL, Cooperberg MR, Freedland SJ: The impact of pathologic staging on the long-term oncologic outcomes of patients with clinically high-risk prostate cancer. Cancer 2014;120:1656-1662.

19 Walsh PC: Radical prostatectomy: a procedure in evolution. Semin Oncol 1994;21:662_ 671.

20 Koch MO: Management of the dorsal vein complex during radical retropubic prostatectomy. Semin Urol Oncol 2000;18:33-37.

21 Epstein JI, Allsbrook WC Jr, Amin MB, Egevad LL: The 2005 International Society of Urological Pathology (ISUP) Consensus Conference on Gleason Grading of Prostatic Carcinoma. Am J Surg Pathol 2005;29:1228_ 1242.

22 Walz J, Graefen M, Huland H: Surgical anatomy of the prostate in the era of radical robotic prostatectomy. Curr Opin Urol 2011; 21:173-178.

23 Kumar RJ, Barqawi A, Crawford ED: Preventing and treating the complications of hormone therapy. Curr Urol Rep 2005;6:217223.

24 Yossepowitch O, Eggener SE, Serio AM, Carver BS, Bianco FJ Jr, Scardino PT, Eastham JA: Secondary therapy, metastatic progression, and cancer-specific mortality in men with clinically high-risk prostate cancer treated with radical prostatectomy. Eur Urol 2008;53:950-959.

25 Miyake H, Fujimoto H, Komiyama M, Fujisawa M: Development of "extended radical retropubic prostatectomy": a surgical technique for improving margin positive rates in prostate cancer. Eur J Surg Oncol 2010;36: 281-286. 